\title{
30 MINUTOS DE FILOSOFÍA DEL DERECHO. VIEJOS Y NUEVOS PROBLEMAS
}

\author{
Ernesto Garzón Valdés \\ Universidad de Mainz
}

RESUMEN. Este trabajo recoge la intervención que cerró el seminario «Derecho, ética y política. Un debate en torno a la obra de Ernesto Garzón Valdés» (Alicante, 15 y 16 de junio de 2007). En ella se recogen algunas reflexiones del autor sobre los problemas cruciales de los que debería ocuparse la filosofía del Derecho contemporánea: 1) Estado de Derecho y terrorismo; 2) el impacto de las investigaciones neurológicas en el concepto de responsabilidad; 3) la erosión de las estructuras institucionales a nivel internacional; 4) la relación entre etica, política y Derecho desde el punto de vista de una filosofía analítica del Derecho; y 5) América Latina como contexto de investigación jurídico-filosófica.

Palabras clave: filosofía del Derecho.

ABSTRACT. This is the closing paper to the Seminar «Derecho, ética y política. Un debate en torno a la obra de Ernesto Garzón Valdés» (Alicante, 15 y 16 de Junio de 2007). It is an approach to the crucial problems for the forthcoming legal philosophy: 1) State of Law and Terrorism;2) the impact of neurological research on the concept of responsibility; 3 ) the undermining of international institutional structures; 4) the connection among ethics, politics and Law for an analytical legal Philosophy; 5) Latin America as a context for legal and philosophical research.

Keywords: Legal Philosophy. 


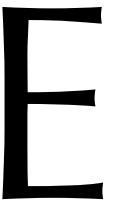

112 de septiembre de 1945, es decir, pocos meses después de terminada la Segunda Guerra Mundial, Gustav RadBruch publicó en el RheinNeckar-Zeitung de Heidelberg un brevísimo pero bien significativo ensayo titulado «Cinco minutos de filosofía del Derecho». El mundo acababa de padecer uno de los más terribles testimonios del fracaso de la razón para combatir la psicosis del odio y la destrucción. La conmoción moral fue tan enorme y el derrumbe institucional europeo alcanzó dimensiones tales que hasta un filósofo del Derecho escépticamente juspositivista como RADBRUCH consideró necesario repensar su posición filósofica. Desde los Estados Unidos, Hans KELSEN contribuía al diseño del documento básico de la nueva Organización de las Naciones Unidas concebida como institución adecuada para contener la agresión bélica en el futuro. Pocos años más tarde, en el ámbito nacional, Alemania sancionaba su Ley Fundamental que serviría luego de modelo a otras constituciones europeas. Un aspecto relevante de estos nuevos marcos constitucionales era la inclusión de un catálogo de derechos fundamentales entendidos no como meros enunciados retóricos o programáticos sino como normas positivas de aplicación directa. La positivación de estos derechos, tanto a nivel nacional como internacional, contribuyó entonces a dar un nuevo tono a la discusión entre jusnaturalistas y juspositivistas dispuestos, algunos de ellos, a aceptar la existencia «real» de derechos humanos.

Hoy, exactamente 61 años después del escrito de RADBRUCH, teniendo en cuenta cómo anda el mundo y las calamidades institucionales que padecemos nacional e internacionalmente, como así también los desafíos con los que se enfrentan los juristas por razones no sólo político-sociales sino también científico-naturales, he pensado que podría ser oportuno inspirarme en el título de aquel trabajo y enunciar algunas cuestiones que pudieran servir de tema de reflexión en este encuentro.

El subtítulo de mi intervención requiere quizás una explicación: un problema puede ser viejo por persistente, porque todavía no se ha encontrado la respuesta adecuada. Pero también puede ser viejo por recurrente, por reaparecer cuando se eliminan las condiciones que hicieron posible su solución en el pasado. Y un problema es nuevo cuando es el resultado de desafíos inéditos o hasta ahora desconocidos. La calificación de un problema como viejo o como nuevo suele depender, además, de la perspectiva que uno adopte; la aceptación de una determinada calificación, de la plausibilidad de los criterios que se invoquen. Presupone también siempre un cierto conocimiento del ámbito en el cual algo es percibido como problema. Las soluciones que la ciencia, el arte y la filosofía pretenden ofrecer no se entienden cabalmente si no se sabe cuáles son los problemas que las requieren. Esto vale tanto para la ecuación masa-energía, el acorde de Tristán o la distinción entre sistemas normativos estáticos y dinámicos. Por lo general, como muchas veces desconocemos el problema, aceptamos sin más la solución que se nos ofrece. Economizamos así tiempo y nos movemos confortablemente arropados por la ignorancia. Claro que conviene siempre andar con cuidado y no crear falsos problemas. No está, por ello, de más recordar la sensata advertencia de Jorge Luis BORGES: 
La palabra problema puede ser una insidiosa petición de principio. [...] Otro demérito de los falsos problemas es el de promover soluciones que también son falsas ${ }^{1}$.

En lo que sigue, procuraré no cometer ninguno de estos dos pecados. Pero necesitaré no cinco sino treinta minutos. Si se acepta la verdad del enunciado según el cual a menor talento mayor tiempo para explicar lo que se tiene en mente, espero se me disculpe la multiplicación de los minutos radbruchianos. Habré de referirme a

1. Estado de Derecho y terrorismo.

2. El impacto de las investigaciones neurológicas en el concepto de responsabilidad.

3. La erosión de las estructuras institucionales a nivel internacional.

4. La relación entre ética, política y Derecho desde el punto de vista de una filosofía analítica del Derecho.

5. América Latina como contexto de investigación jurídico-filosófica.

\section{II}

La agresión terrorista del 11 de septiembre de 2001 y las subsiguientes de Madrid y Londres han significado no sólo una tragedia desde el punto de vista de las víctimas que causaran sino que también tienen serias implicaciones internas e internacionales por lo que respecta a la salvaguarda de las instituciones democráticas del Estado de Derecho.

Vivimos tiempos en los que no pocos consideran que se requieren competencias del Estado que ya «no tienen cabida dentro de los principios del Derecho». Estas competencias significan la renuncia a máximas básicas del sistema jurídico democrático; se produce entonces una «exclusión de los derechos fundamentales» ${ }^{2}$, que son ahora contrapuestos a los intereses colectivos. Vuelve a plantearse, por ejemplo, la cuestión acerca de si los números cuentan cuando se trata de salvar vidas en peligro. Tanto a nivel teórico como práctico-legislativo existen ya abundantes testimonios de una tendencia a admitir el sacrificio de los derechos individuales en aras de la seguridad colectiva. El principio de la dignidad humana - que podría ser considerado como el presupuesto conceptual de los derechos humanos- parece haber quedado acorralado ante las exigencias de una supuestamente eficaz defensa frente al terrorismo.

Una sociedad atemorizada por la agresión terrorista es impulsada a refugiarse ideológicamente en posiciones radicalizadas que reducen las posibilidades del diálogo político. Las actitudes se polarizan y no pocos prefieren manifestar su lealtad incondicionada a quienes detentan el poder político a fin de no ser tildados de «culpables por asociación», es decir, «simpatizantes de los terroristas» ${ }^{3}$. Pero la lealtad incondicionada reduce necesariamente la capacidad de crítica, virtud democrática por excelencia.

\footnotetext{
1 Borges, 1974: «Las alarmas del doctor Américo Castro», del mismo autor, Obras completas, Buenos Aires: Emecé, 2 vols., vol. 1, pp. 653-657, p. 653.

2 Merkel, 2005: «Wenn der Staat Unschuldige opfert», en Die Zeit, del 8 de julio.

3 Cfr. CReshaw: «Reflections on the Ethics of Terrorism», en CREnSHAW (ed.), 1982: Terrorism, Legitimacy and Power, Middletown, Conn.: Wesleyan University Press, pp. 1-37, p. 16.
} 
Si, a diferencia de lo que postulaba Carl SchmitT en tiempos de la República de Weimar, se considera, como creo que es correcto, que el ámbito de la política democrática no es el de la confrontación amigo-enemigo sino el de la negociación y el compromiso, no cuesta mucho inferir que el maniqueísmo político, con su secuela de sospechas recíprocas, denunciaciones y pretendida posesión de la verdad absoluta, es una ladera resbaladiza que conduce a lo que David HeLD llama «abdicación de la política» ${ }^{4}$.

La democracia es sólo justificable si se somete a restricciones constitucionales. A fines de los años veinte del siglo pasado, Hans KELSEN formuló el «principio de la mayoría», basado en el respeto de los derechos individuales fundamentales, como base justificatoria de la democracia y barrera contra el «dominio de la mayoría». Posiblemente su trasfondo neokantiano le hacía confiar más en las instituciones que en una rousseauniana creencia en la bondad ciudadana o en la humeana simpatía de los seres humanos. Para que la democracia de «una persona, un voto» no degenere en el dominio dictatorial de la mayoría, es necesario contar con las «muletas morales» de los derechos fundamentales no negociables, inmunes a las decisiones políticas, es decir, hay que respetar aquello que suelo llamar el «coto vedado» de las constituciones democráticas. Norberto BoBBio recurrió también a una metáfora geográfica (similar a la del coto) al referirse a la inviolabilidad de los derechos del hombre y del ciudadano establecida en todas las constituciones liberales:

Por su carácter de inalienables frente a cualquier decisión mayoritaria estos derechos fueron llamados derechos contra la mayoría. [...] La amplia esfera de los derechos de libertad puede interpretarse como una especie de territorio fronterizo ante el cual se detiene la fuerza del principio mayoritario 5 .

Son las «muletas morales» las que ahora corren peligro. En el ámbito jurídico, ya hay quienes, como Günther JACOBS, proponen un Derecho penal del enemigo y Guantánamo como prisión modélica del Estado occidental contemporáneo. Pienso que a un filósofo del Derecho democrático no puede serle indiferente este deterioro institucional que amenaza colocarnos en una situación pre-ilustrada y pre-liberal, con intérpretes privilegiados de lo que conviene al bien común de una sociedad. Un régimen jurídico democrático que pretenda prescindir de las «muletas morales» avanzará a los tumbos hacia su derrumbe autoculpable. Reaparecerá así un viejo problema: el de la conciliación de los intereses privados del ciudadano y la vigencia de instituciones que los orientan y restringen.

\section{III}

A partir, sobre todo, de los experimentos neurológicos realizados en los años ochenta del siglo pasado por Benjamin LIBET, la vieja discusión acerca de hasta qué punto somos libres autores de nuestro comportamiento ha despertado renovado interés no sólo entre científicos del cerebro y filósofos puros sino también entre filósofos del Derecho

\footnotetext{
${ }^{4}$ Cfr. Held, 2001: «Violencia y justicia en una era mundial», en El País, del 19 de septiembre.

5 BobBIO, 2003: Teoría general de la política, edición de BOVERO, traducción de DE CABO, y PISARELLO, Madrid: Trotta, pp. 478 y s. (subrayado de EGV).
} 
y penalistas. En un mundo causalmente cerrado — se afirma - no tiene cabida la posibilidad de elegir entre diversos cursos de acción. Si se acepta la teoría de la evolución, se rechazan las concepciones creacionistas de origen mítico-religioso y se toma en cuenta que el genoma humano está ya íntegramente investigado, no hay cabida para la inserción de algo así como un elemento espiritual, de un «fantasma en la máquina», como diría Gilbert RYLE. No existe un correlato neuronal de la conciencia. Los argumentos que se aducen ya no son únicamente filosóficos sino que pretenden sustentación empírico-científica.

En Alemania, Wolf SINGER, director del Instituto Max Planck de investigaciones del cerebro, afirma rotundamente:

Todas (las) manifestaciones del comportamiento [...] pueden ser [...] remitidas a procesos neuronales en el sentido de una relación causal. [...] El cerebro humano casi no se diferencia en nada del de los animales; [...] Dado que con respecto al cerebro de los animales no tenemos ningún motivo para dudar que todo el comportamiento se basa en funciones del cerebro y, por lo tanto, está sometido a las leyes deterministas de procesos físico-químicos, la tesis del condicionamiento material del comportamiento debe valer también para las personas. [...] Las células nerviosas de un caracol funcionan según los mismos principios que las células nerviosas de la corteza cerebral humano. [...] Esto nos conduce a la muy desagradable conclusión de que todo lo que hace que seamos lo que somos y nos diferencia de los animales y, por lo tanto, todo lo que posibilita nuestra evolución cultural se basa en un aumento cuantitativo de una determinada estructura cerebral ${ }^{6}$.

A partir de estas consideraciones, los partidarios de las nuevas investigaciones cerebrales incursionan en el ámbito de la responsabilidad jurídico-penal:

Esta intelección podría conducir a un juicio más humano, menos discriminante de nuestros congéneres que tuvieron la mala suerte de llegar a la mayoría de edad con un órgano cuya arquitectura funcional no les permite ningún comportamiento adecuado. Condenar a las personas que poseen disposiciones problemáticas de comportamiento como malas o perversas sólo significa evaluar el resultado de un desarrollo fatal del órgano que constituye nuestro ser.

\section{[...]}

Esta forma de ver las cosas tendría en cuenta el trivial conocimiento de que una persona hizo lo que hizo porque en el momento en cuestión no pudo hacer otra cosa ya que si así no fuera habría actuado diferentemente. Como en el caso particular no es posible nunca tener una visión completa de los determinantes de una decisión, la jurisprudencia seguirá orientándose por reglas pragmáticas. Pero valdría la pena someter a la praxis actual, a la luz de los conocimientos de la investigación del cerebro, a un examen de coherencia ${ }^{7}$.

Adversarios de las conclusiones de los investigadores del cerebro, como Jürgen HABERMAS, sostienen que las explicaciones del comportamiento humano tienen que estar referidas a razones y no a relaciones causales cerradas ${ }^{8}$. Sabemos más que hace cien años acerca de cómo funciona el cerebro pero no hemos llegado a una respues-

${ }^{6}$ SINGER, 2004: «Verschaltungen legen uns fest: Wir sollten aufhören, von Freiheit zu sprechen», en GEYER, C. (ed.), Hirnforschung und Willensfreiheit. Zur Deutung der neuesten Experimente, Francfort: Suhrkamp, pp. $30-65$, pp. 36 y ss.

7 SINGER, 2004: 63 y ss.

${ }^{8}$ Cfr. Habermas, 2005: «Freiheit und Determinismus», en Zwischen Naturalismus und Religion, Francfort del Meno: Suhrkamp, pp. 155-186. 
ta satisfactoria de cuestiones centrales tales como la relación entre las estructuras materiales y los procesos de conciencia, o entre los procesos electrofisiológicos y constructos complejos como autoconciencia, voluntad, motivación, evaluación moral ${ }^{9}$. Se aduce, además, que lejos de ser una ficción, el concepto de culpa constituye una buena defensa frente a «condenas arbitrarias»; tendría una función «restringente» y protectora de la dignidad humana. Por lo tanto, «las sociedades democráticas y liberales deberían procurar movilizar a sus Constituciones en favor de este tipo de decisiones» ${ }^{10}$.

Es probable que la discusión acerca de las consecuencias penales de la investigación del cerebro continúe y ocupe también la atención de filósofos del Derecho. Se ha creado una especie de «mitología del cerebro» ${ }^{11}$, que llega al gran público a través de presentaciones populares (algo que no sucedía con la tradicional filosofía de la mente de la que John SEARLE es un buen representante).

¿Es éste un problema viejo o nuevo? Me inclino a pensar que es un problema viejo-persistente. Friedrich NIETZSCHE escribió páginas memorables acerca de la función del juez y la imposibilidad lógica de que un partidario del libre albedrío pudiera imponer penas. En efecto, si se aceptaba el libre albedrío como explicación de una acción delictiva ello significaba que el actor había actuado sin condicionamiento alguno: «el acto sucede como un milagro, surge de la nada. [...] El delincuente es castigado porque hace uso de la "libre voluntad", porque ha actuado sin razón alguna». Pero, en verdad, no debería ser castigado pues sólo puede ser castigado quien es responsable de su acto, por haber actuado según razones ${ }^{12}$.

El problema de la relación mente-cuerpo aún no ha sido solucionado. Seguimos viviendo, como diría Georg Henrik vON WRIGHT, a la sombra de DESCARTES. SPINOZA propuso en su hora una especie de dualidad de perspectiva:

la substancia pensante y la substancia extensa son una sola y misma substancia aprehendida ya desde un atributo, ya desde otro. Así también un modo de la extensión y la idea de dicho modo son una sola y misma cosa, pero expresada de dos maneras» ${ }^{13}$.

Y en nuestro tiempo VON WRIGHT afirmaba:

La concepción según la cual la mente y la materia son dos aspectos de lo que es real es quizás la mejor vía para concebir la doble relación de mente y materia. Esta concepción no es —o así me parece- totalmente diferente de la de Spinoza» ${ }^{14}$.

Sin duda no lo es. Pero el problema persiste y pienso que no puede ser eludido por un filósofo del Derecho.

\footnotetext{
9 KRÖBER: «Die Hirnforschung bleibt hinter dem Begriff strafrechtlicher Verantwortlichkeit zurück», en GEYER, C. (ed.), 2004: pp. 103-110, p. 104.

${ }^{10}$ LÜDERSEN: «Ändert die Hirnforschung das Strafrecht?», en GEYER, C. (ed.), 2004: pp. 98-102, pp. 101 y ss.

${ }^{11}$ Cfr. MAYER: «Ach, das Gehirn. Über einige neue neurowissenschaftliche Publikationen», en GEYER (ed.), 2004: pp. 205-217, p. 212.

${ }_{12}$ Cfr. NietzSCHe, 1954: «Menschliches, Alzumenschliches», vol. 2., 23, en Werke, 3 vols., Múnich: Hanser, vol. 1, pp. 887 y ss.

${ }_{13}$ Ética, Parte II, Prop. VII, Escolio.

${ }^{14}$ VON WRIGHT, 1999: «Notes on the philosophy of mind», en In the shadow of Descartes, Dordrecht: Kluwer, pp. 97-123, p. 109.
} 


\section{IV}

En el ámbito internacional asistimos a un proceso de erosión institucional que, en parte, es similar al producido a nivel nacional. También aquí se intenta negar vigencia a las restricciones morales al ejercicio de la soberanía estatal.

Basten, como ejemplo, las objeciones presentadas recientemente por la administración Bush en contra del artículo 3 común de las cuatro Convenciones de Ginebra de 1949 que establece una serie de pautas humanitarias mínimas que deben ser respetadas en caso de conflicto. Entre ellas figuran la prohibición de la tortura, de la toma de rehenes, de ofensas a la dignidad personal, de tratamientos humillantes y degradantes, de la imposición de sentencias no dictadas por un tribunal legítimo de acuerdo con las garantías judiciales reconocidas como indispensables por las naciones civilizadas. Estas prescripciones fueron en su hora consideradas como universalmente válidas «en todo tiempo y en todo lugar». Actualmente, según el gobierno del país más poderoso del mundo, ellas son demasiado vagas e imposibilitan la lucha contra el terrorismo.

Ya KELSEN había subrayado que todo acto de violencia, tanto a nivel nacional como internacional, o es un delito o es una sanción. Y así como en el Estado se logra la pacificación interna mediante la centralización del empleo de la fuerza como sanción impuesta a la comisión de un delito, así también en el plano internacional la paz sólo se alcanzaría si se centralizaba - a través de la creación de un Estado Federal Mundialel empleo de la fuerza y se mantenía la distinción básica entre delito y sanción.

El primer paso hacia el establecimiento de un Estado Federal Mundial era la creación de un tribunal internacional, con jurisdicción obligatoria. Si cada Estado es juez y parte en la evaluación de sus conflictos internacionales, es decir, que

Mientras no sea posible privar a los Estados interesados de la prerrogativa de decidir la cuestión del Derecho y transferirla de una vez por todas a una autoridad imparcial, a saber a un tribunal internacional, es completamente imposible el progreso en el camino de la pacificación del mundo ${ }^{15}$.

El Consejo de Seguridad, se propone cumplir, de alguna manera, el papel que KELSEN asignaba a una instancia encargada de resolver los conflictos graves entre los Estados miembros y autorizar el uso de la fuerza como sanción. La creación de la Corte Penal Internacional constituye también un paso decisivo en la aplicación individualizada de la sanción y el castigo de delitos que lesionan la «conciencia de la humanidad». No es necesario recordar ahora hasta qué punto concepciones tales como «guerras preventivas» $\mathrm{o}$ «intervenciones armadas» han socavado la función instiucional del Consejo de Seguridad. La no adhesión de los Estados Unidos al tratado fundacional de la Corte Penal Internacional ha traído como consecuencia la extensión de la impunidad a los ciudadanos de la mayor potencia mundial que, de esta manera, se coloca en una posición de legibus solutus.

Los intentos de establecer una dominación unipolar apuntan peligrosamente a la imposición del gobierno del más fuerte, a la implantación de un soberano de facto que, en tanto tal, tiene que colocarse al margen del Derecho. Por razones conceptuales, es

${ }^{15}$ KELSEN, 2003: La paz por medio del Derecho, traducción de ECHÁVARRI, L., introducción de LA TORRE, y García PASCUA, Madrid: Trotta, p. 47. 
obvio que un Estado que apunte a la dominación exclusiva tiene que avanzar a través de una vía que elimine todo tipo de restricción jurídica. Ningún soberano, en el sentido fuerte de la palabra, puede estar sujeto a restricciones jurídicas. Por ello no es casual que los aspirantes a la soberanía mundial prescindan en sus decisiones de los criterios de legalidad que impone el de por sí eficazmente débil Derecho internacional. Razones de coherencia conceptual requieren la no aceptación por parte del soberano de las limitaciones de un «coto vedado».

Por supuesto que si tal es el caso, la estabilidad del sistema impuesto al margen de limitaciones jurídicas es precaria. Ésta es una consideración que, desde luego, difícilmente convencerá a quien se considere lo suficientemente fuerte como para imponer su voluntad. Pero conviene no olvidar que toda disposición de regulación de comportamiento personal o estatal basada meramente en un acto de voluntad, al margen de las buenas razones de la moral, es sinónimo de despotismo.

Desde el punto de vista moral, es obvio que el despotismo es injustificable. Como ya lo decía LEIBNIZ, ni siquiera Dios puede imponerse voluntaristamente. También Dios, para distinguirse del Diablo, tiene que respetar las razones morales. No puede ser un mero soberano de facto.

Vistas así las cosas, el jurista interesado en la conformación del orden internacional asiste a un notorio deterioro de las instituciones que fueran concebidas como frenos a la agresión bélica y al control del ejercicio del poder estatal. La calamidad de la guerra es uno de los más graves viejos problemas persistentes que todos padecemos.

\section{V}

Sé muy bien que no es fácil definir con precisión qué ha de entenderse por «filosofía analítica». Georg Henrik VON WRIGHT hablaba ya a comienzos de la década de los noventa del siglo pasado de una «confusa heterogeneidad» y Richard RORTY había afirmado diez años antes: «No creo que exista ya algo identificable como "filosofía analítica" ${ }^{16}$. En todo caso - y para facilitar la comprensión de lo que sigue- propongo entender por filosofía analítica la corriente de pensamiento iniciada a comienzos del siglo XX en Gran Bretaña por Bertrand Russell y George Edward MOORE y en Viena por Moritz SCHLICK y Rudolf CARNAP, entendida parcialmente como reacción en contra del Idealismo de KANT y HEGEL y como un positivismo enriquecido con los instrumentos de una nueva lógica ${ }^{17}$. En los años cuarenta a sesenta del siglo pasado, Oxford se convirtió en el centro de una versión de la filosofía analítica inspirada principalmente en el último WiTTGENSTEIN y que podría ser llamada «filosofía del lenguaje ordinario». No pocos brillantes juristas latinoamericanos pasaron temporadas más o menos largas en Oxford y contribuyeron notablemente a dotar de claridad y precisión al lenguaje del Derecho.

SCHLICK había subrayado que la principal función de la filosofía era aclarar el significado de las palabras, contribuir a eliminar la superstición y los prejuicios. En cultu-

${ }^{16}$ Cfr. VON WRIGHT, 1993: «Analytical Philosophy», en The Tree of Knowledge and Other Essays, Leiden/New York/Köln: E. J. Brill, pp. 24-52, p. 41.

17 Ibidem, p. 34. 
ras como las nuestras, tan proclives a la aceptación dogmática de principios de autoridad y a la identificación de lo confuso con lo profundo, el cultivo de la filosofía analítica ejerció una influencia benéfica, pues contribuyó decididamente a la adopción de una actitud eminentemente crítica y cautelosamente escéptica.

Esto, por una parte. Pero, por otra, un quizás excesivo talante crítico contribuyó también a que uno de los rasgos más sorprendentes de la filosofía analítica fuera el descuido durante largas décadas por parte de sus representantes más importantes de temas centrales de la filosofía política, la ética y la metafísica. En 1956, Peter LASLETT podía, por ello, formular un lapidario diagnóstico: «Actualmente la filosofía política está muerta» ${ }^{18}$.

Durante las tres primeras décadas del siglo Xx, se impuso cada vez con mayor vigor la tendencia a la separación entre las ciencias sociales y la ética. Dos ejemplos significativos pueden ilustrar esta afirmación.

En 1935, Lionel RobBins publicó, bajo el título Essay on the Nature and Significance of Economic Science, un libro que es considerado como una obra clásica por lo que respecta a las relaciones entre ética y economía. En su versión fuerte, la tesis central de ROBBINS sostenía la necesidad de establecer una distinción tajante entre los ámbitos de investigación de ambas disciplinas. En su versión débil, la tesis afirmaba que, si se quería hablar de una economía normativa, lo único que podía aceptarse era la formulación de reglas para el uso de recursos escasos, dentro del marco de un mercado perfectamente libre, con miras a la obtención de fines dados de antemano. La justificación de estas reglas sería, pues, hipotética: valdría sólo en relación con ciertos fines u objetivos y sólo para aquellos individuos que los aceptan o comparten. La justificación de los fines, en cambio, superaría los límites de la razón y al respecto lo más sensato sería guardar silencio. En su versión débil, la tesis de RoBBins adoptaba una posición ética no cognoscitivista.

En el campo de la filosofía del Derecho, Hans KeLSEN publica en 1934, es decir, un año antes que el libro de RoBBINS, su Reine Rechtslehre. En esta obra, con argumentos similares a los de RoBBins, aboga por una separación radical entre Derecho y ética. Justamente una de las delimitaciones que, según KELSEN, deben asegurar la «pureza» del Derecho es la de la separación entre Derecho y moral.

Pero, al igual que RoBBINS, KELSEN admitía la posibilidad de una justificación hipotética de los valores y había dado un ejemplo de ello en sus estudios sobre justificación de la democracia publicados en la década del veinte.

Desde el punto de vista estrictamente filosófico, las posiciones de RobBins y de KELSEN contaban con el apoyo de la obra de Max WEBER y Hans REICHENBACH y, sobre todo de Julius AYER quien en 1936 publica su Language, Truth and Logic en donde los juicios éticos quedan reducidos a expresiones de estados de ánimo de aprobación o de rechazo. Alf Ross recogería esta versión emotivista de la ética en su libro Sobre el Derecho y la justicia, en el que sostenía que decir que algo es justo era equivalente a dar un puñetazo sobre una mesa como señal de aprobación. No es necesario entrar aquí en

${ }_{18}$ Citado según Pettit, 1993: «The contribution of analytical philosophy», en Goodin y PetTit (eds.), A Companion to Contemporary Political Philosophy, Oxford: Blackwell, pp. 7-38, p. 8. 
la consideración de los esfuerzos realizados casi en esos mismos años por Charles STEVENSON para procurar crear un marco racional a las discusiones éticas signadas por el emotivismo, con su distinción entre desacuerdos en actitudes y desacuerdos en creencias. Lo que me importa señalar es que, hasta la década de los sesenta, la posición no cognocitivista fue la predominante en la filosofía política y jurídica de orientación analítica.

Pero ya en 1959 Stanley Benn y Richard PeTERS publicaron Social Principles and the Democratic State; en 1961, H. L. A. HART, The Concept of Law y en 1965 Brian BARRY, Political Argument. La verdadera conmoción se produce, desde luego con la publicación en 1971 de $A$ Theory of Justice de John RaWLs. Esta obra fundamental provocó reacciones de crítica o de rechazo pero el camino estaba despejado para una discusión interna dentro de la corriente analítica. Basta pensar en autores como R. M. HARE, Richard BRANDT, Joseph RAZ o Ronald DwORKIN.

Por lo que respecta a versiones metafísicas desde una perspectiva analítica, quizás Stuart HAMPSHIRE con sus estudios sobre SPINOZA ha sido quien con mayor claridad ha puesto de manifiesto la posibilidad de elaborar un justificación metafísica del individualismo en la ética y la política. En efecto, según HAMPSHIRE, la teoría de las pasiones de SPINOZA

trata de mostrar que un orden social civilizado, basado en la libertad de pensamiento y en la tolerancia, es una condición necesaria para el uso de la razón y, por consiguiente para la realización del individuo y el goce de sus poderes activos ${ }^{19}$.

Estas reflexiones de un excelente filósofo analítico pueden contribuir quizás a una rehabilitación sensata de la metafísica como intento de respuesta a perplejidades permanentes de todo ser racional.

\section{VI}

Hasta ahora me he referido a viejos y nuevos problemas de la filosofía del Derecho desde una perspectiva que me gustaría fuera considerada como analítica si es que por ella ha de entenderse una preocupación por

Luchar en contra de toda forma de efectos de oscurecimiento de las palabras en la mente de las personas... ${ }^{20}$

Pero cuando esta lucha se realiza en América Latina o en Europa con la mirada puesta en América Latina, no hay que olvidar que aquí pasa justamente lo opuesto a lo que según Philip PeTtiT sucedía en los países de residencia de los filósofos analíticos durante buena parte del siglo XX:

La mayoría de los filósofos analíticos vivía en un mundo en donde valores tales como libertad, igualdad y democracia mantenían un dominio indiscutible ${ }^{21}$.

Nuestro mundo es muy diferente al descrito por PетTiт. El filósofo del Derecho latinoamericano no puede olvidar que trabaja en un continente en donde las institucio-

\footnotetext{
${ }^{19}$ Hampshire, 2005: Spinoza and Spinozism, Oxford: Clarendon Press, p. 198.

${ }^{20}$ VON WRIGHT, 1993: 50.

${ }^{21}$ PetTit, 1993: 10.
} 
nes juegan un papel tan peculiar que algún candidato a presidente puede proclamar a voz en cuello:

Al diablo las instituciones ${ }^{22}$.

sin que ello sea interpretado por el electorado que le dio su voto como una contradicción pragmática: quien desea ocupar el cargo institucional más alto manda al diablo las instituciones a cuyo frente desearía estar.

Hay que reconocer, desde luego, que la desconfianza ante las instituciones tiene ya en América Latina una tradición secular. En muchas partes de nuestro continente sigue siendo cierta la observación formulada en 1888, por el fino intelectual peruano Manuel GONZÁLEZ PRADA:

Hay un hecho revelador: reina mayor bienestar en las comarcas más distantes de las grandes haciendas, se disfruta de más orden y tranquilidad en los pueblos menos frecuentados por las autoridades ${ }^{23}$.

Que la ausencia del poder estatal pueda ser garantía de paz social, es algo que sin duda sorprendería a HOBBES pero no a quien esté familiarizado con nuestra precariedad institucional.

Esta insuficiencia institucional trae como consecuencia la necesidad de una especie de traducción adaptativa de los temas que filósofos del Derecho trabajan en Europa o en los Estados Unidos. Cuestiones tales como las vinculadas con la función judicial y la interpretación del Derecho, las garantías constitucionales, los criterios de legitimidad o la identificación de la regla de reconocimiento necesariamente tienen que ser vistas con una óptica que tenga en cuenta que en no pocos de nuestros países quienes detentan el poder real son «políticos de raza», es decir, «oportunistas con principios» según una definición supuestamente laudatoria de un conocido politólogo argentino ${ }^{24}$. Dicho con otras palabras, en buena parte de América Latina sigue vigente la cínica frase del personaje de una memorable novela de Alejo CARPENTIER:

como decimos allá, «la teoría siempre se jode ante la práctica» y «jefe con cojones no se guía por papelitos» ${ }^{25}$.

Si esto es así, pienso que no es muy aventurado sugerir que la tarea de un filósofo del Derecho en nuestras latitudes es doblemente complicada: por una parte, no puede dejar de tomar en cuenta, entre otros, los problemas que he tratado de enunciar aquí; por otra, tiene que tratar de desgarrar el velo de la retórica y esquivar la trampa de la ciega imitación de modas filosóficas. Hay ya buenos ejemplos al respecto pero no es poco lo que queda por hacer. Por mi parte, tengo ahora que callar: se acabó mi tiempo (sólo en esta reunión, desde luego).

22 LÓPez ObRador: Cfr. El País, del 3 de septiembre de 2006, p. 5.

23 González Prada, 1987: «Nuestros indios», en GonZÁlez Prada, Páginas libres. Horas de lucha, Caracas: Ayacucho, pp. 332-343, p. 343.

${ }^{24}$ José Nun sobre Néstor Kirchner en La Nación, del 9 de julio de 2006, p. 20.

25 CARPENTIER, 1976: El recurso del método, Madrid: Siglo XXI, p. 31. 